COSTING:Journal of Economic, Business and Accounting

Volume 4 Nomor 2, Juni 2021

e-ISSN : 2597-5234

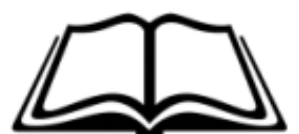

IDMEKp:

\title{
ANALISIS FINANSIAL DISTRESS UNTUK MEMPREDIKSI RISIKO KEBANGKRUTAN PERUSAHAAN SUB SEKTOR ENERGI
}

\section{FINANCIAL DISTRESS ANALYSIS FOR PREDICTING THE RISK OF SUBSCRIPTION IN ENERGY SUB-SECTOR COMPANIES}

\author{
Pauline Cielo ${ }^{1}$, Gusganda Suria Manda ${ }^{2}$ \\ Universitas Singaperbangsa Karawang, Indonesia ${ }^{1,2}$ \\ 1710631030144@student.unsika.ac.id ${ }^{1}$
}

\begin{abstract}
This study aims to determine and analyze the financial performance of the energy subsector using the Almant Z-Score method. This research is a quantitative descriptive study. The population in this study are energy sub-sector companies listed on the Indonesia Stock Exchange 2015-2019. The sample in this study amounted to 4 energy sub-sector companies, namely PT. Perusahaan Gas Negara, PT. Leyand International, PT. Rukun Raharja, and PT. Mitra Energi Persada. The sampling technique in this study was using purposive sampling technique. The results of the financial distress predictions for the energy sub-sector companies, amounting to 4 publicly traded companies during the 2015 to 2019 research period using the Altman Z-Score method. This results in three companies in financial distress and one company in a safe area.
\end{abstract}

Keywords: Finansial Distress, Bankrupty, Energy Sub-sector

\begin{abstract}
ABSTRAK
Penelitian ini bertujuan untuk mengetahui dan menganalisis kinerja keuangan sub sektor energy dengan menggunakan metode Almant Z-Score. Penelitian ini adalah penelitian deskriptif kuantitatif. Populasi dalam penelitian ini adalah perusahaan sub sektor energy yang terdaftar di Bursa Efek Indonesia 2015-2019. Sampel dalam penelitian ini berjumlah 4 perusahaan sub sektor energy, yaitu PT. Perusahaan Gas Negara, PT. Leyand International, PT. Rukun Raharja, dan PT. Mitra Energi Persada. Teknik pengambilan sampel dalam penelitian ini menggunakan teknik purposive sampling. Hasil prediksi financial distress perusahaan sub sektor energy yang berjumlah 4 perusahaan go public selama periode penelitian 2015 sampai 2019 dengan menggunakan metode Altman Z-Score. Menghasilkan bahwa terdapat tiga perusahaan dalam kondisi finansial distress dan terdapat satu perusahaan yang berada pada safe area.
\end{abstract}

Kata Kunci: Kebangkruan, Kebangkrutan, Sub Sektor Energi 


\section{PENDAHULUAN}

Kondisi umum sektor energi Indonesia dicerminkan oleh beberapa karakteristik. Pertama, kebutuhan yang lebih besar dibandingkan pasokan dengan kecenderungan permintaan yang meningkat di masa-masa yang akan datang. Salah satunya adalah perubahan populasi sangat mempengaruhi besaran dan komposisi permintaan energi, baik langsung maupun akibat dari dampak yang ditimbulkannya terhadap perkembangan ekonomi.

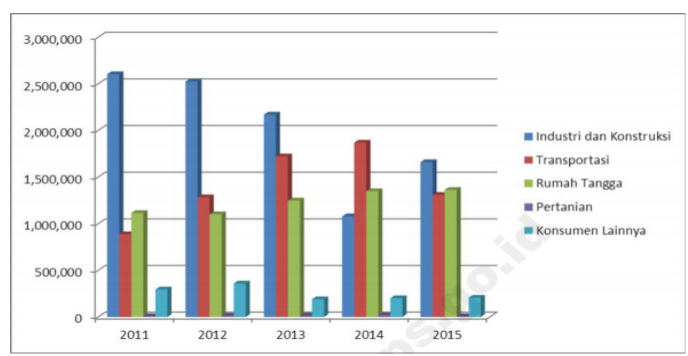

Gambar 1 Komsumsi Energi Menurut Sektor (Sumber: Badan Pusat Statistik (2020)

Berdasarkan gambar 1 menunjukan bahwa konsumsi energi akhir perkapita di Indonesia tahun 2015 mencapai 7.027.506 rupiah atau sekitar $14,4 \%$ dari PDB per kapita. Dibandingkan dengan tahun 2014, produksi energi primer per kapita Indonesia tahun 2015 mengalami penurunan sebesar $0,2 \%$.

Faktor kedua adalah sektor energi Indonesia memiliki ketergantungan yang tinggi pada bahan bakar fosil.

Faktor kedua adalah sektor energi Indonesia memiliki ketergantungan yang tinggi pada bahan bakar fosil.

\begin{tabular}{llll}
\multicolumn{1}{c}{ Tabel 1 } & $\begin{array}{l}\text { Perkembangan } \\
\text { Primer }\end{array}$ & Bauran & Energi \\
\hline Energi & Permitaan & Produksi & Satuan \\
\hline Batu Bara & $177,600,000$ & $555,000,000$ & Ton/hari \\
\hline Minyak Bumi & 248,960 & 778,000 & $\mathrm{Bph}$ \\
\hline Gas & 812,000 & $2,900,000$ & $\mathrm{Mmscf}$ \\
\hline $\begin{array}{l}\text { Energi Baru } \\
\text { Terbarukan }\end{array}$ & 423 & 4,706 & $\mathrm{KL} / \mathrm{hari}$ \\
\hline
\end{tabular}

Sumber: Kementrian ESDM (2020)
Berdasarkan tabel 1 perkembangan bauran energi primer di Indonesia menunjukan bahwa 91\% kebutuhan energi Indonesia masih dipasok dari sumber-sumber energi tidak terbarukan (Batu Bara, Minyak Bumi, dan Gas)

Pertumbuhan penjualan adalah peningkatan jumlah penjualan dari tahun ke tahun atau dari waktu ke waktu. Pertumbuhan penjualan mencerminkan keberhasilan investasi pada periode masa lalu dan dapat dijadikan sebagai prediksi pertumbuhan masa yang akan datang (Carnevela, 2017).

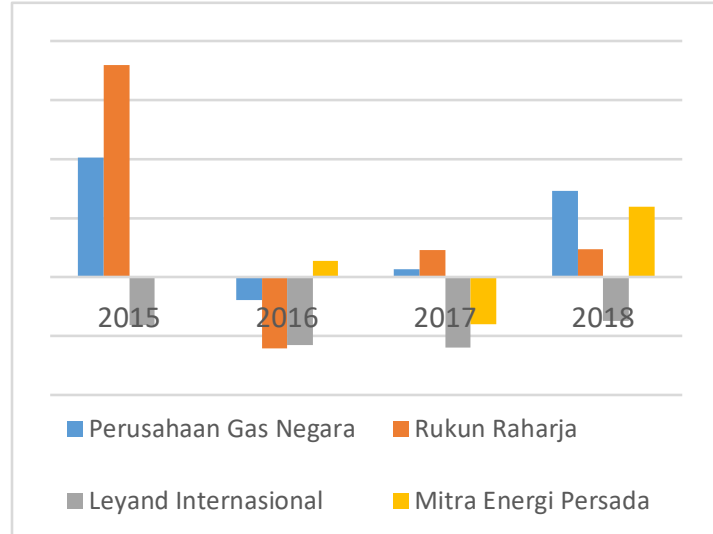

Gambar 2 Pertumbuhan Pendapatan
Perusahaan Energi (Sumber:
Bursa Efek Indonesia, 2020)

Berdasarkan gambar 2 menunjukan bahwa peningkatan atau penurunan penjualan mengakibatkan perubahan harga saham perusahaan sub sektor energi. Penurunan pendapatan pada tahun 2018 serta perusahaan sub sektor energi tidak bisa menjaga kestabilan atau peningkatan penjualan setiap tahunnya.

Berkembangnya suatu perusahaan dari perusahaan kecil hingga menjadi besar tidak lepas dari peran manajer perusahaan dalam mengelola sumber daya pemilik perusahaan (Hariyani et al. 2011). Semakin besar ukuran sebuah perusahaan (size) yang 
dapat dilihat dari besarnya total aset sebuah perusahaan.

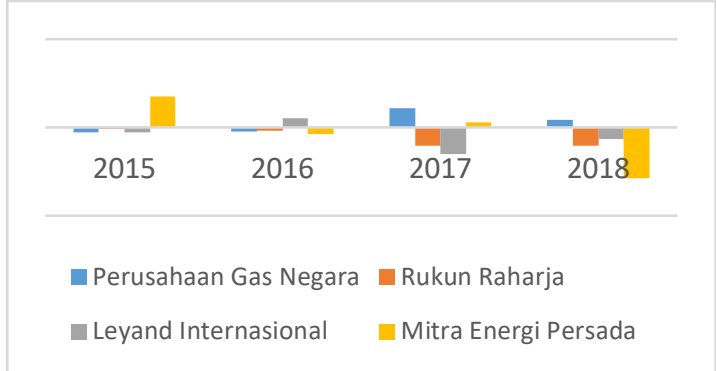

Gambar 3 Pertumbuhan Aset Perusahaan Energi (Sumber: Bursa Efek Indonesia, 2020)

Pada gambar 3 menunjukan bahwa perusahaan sub sektor energy mengalami penurunan pertumbuhan aset pada tahun 2018.

Financial distress adalah suatu keadaan dimana sebuah perusahaan mengalami kesulitan untuk memenuhi kewajibannya, keadaan dimana pendapatan perusahaan tidak dapat memenuhi total biaya dan mengalami kerugian. Bagi kreditor keadaan ini merupakan gejala awal kegagalan debitor (Hery, 2017)

Ada berberapa model atau metode mengenai perhitungan finansial distress yang lazim digunakan oleh perusahaan adalah model Altman ZScore.

Model Altman Z-Score dikembangkan oleh seorang peneliti berkebangsaan Amerika Serikat yang bernama Edward I. Altman pada 1969, dengan menggunakan rasio-rasio keuangan. Altman telah mengkombinasikan beberapa rasio menjadi model prediksi dengan model statistik. Tingkat ketepatan prediksi untuk model Altman yang telah direvisi mencapai 95\%

Menurut Platt dalam Fahmi (2017), berpendapat bahwa financial distress adalah tahap penurunan kondisi keuangan yang dialami oleh suatu perusahaan, yang terjadi sebelum terjadinya kebangkrutan ataupun likuidasi.

Model Z-Score pertama Altman digunakan untuk memprediksi kebangkrutan pada perusahaanperusahaan terbuka (manufaktur) yang telah listing di bursa saham. Model ini diciptakan pertama kali oleh Altman pada tahun 1968 dengan metode Multiple Discriminant Analysis untuk mengetahui besaran koefisien setiap variabel dalam model Z-Score nya.

\section{METODE PENELITIAN}

Metode penelitian pada dasarnya merupakan suatu cara ilmiah untuk mendapatkan data dengan tujuan dan kegunaan tertentu. Metode dalam penelitian ini adalah metode penelitian deskriptif kuantitatif. Model financial distress dalam penelitian ini menggunakan model Altman Z-score. Populasi dalam penelitian ini adalah perusahaan sub sektor energy yang terdaftar di Bursa Efek Indonesia. Sampel dalam penelitian ini berjumlah 4 perusahaan sub sektor energy, yaitu PT. Perusahaan Gas Negara, PT. Leyand International, PT. Rukun Raharja, dan PT. Mitra Energi Persada. Teknik pengambilan sampel dalam penelitian ini menggunakan teknik purposive sampling dengan kriteria:

1. Perusahan Sub Sektor Energi yang terdaftar di Bursa Efek Indonesia selama periode 2015-2019

2. Perusahaan rutin mempublikasikan laporan keuangan dan tidak pernah delisting di Bursa Efek Indonesia selama 2015-2019 
HASIL DAN PEMBAHASAN

Hasil Analisis Financial Distress

Metode Altman Z-score PT.

Perusahaan Gas Negara

Tabel 2 Hasil Perhitungan Z-Score PT.Perusahaan Gas Negara

\begin{tabular}{llllll}
\hline Tahun & $\mathbf{2 0 1 5}$ & $\mathbf{2 0 1 6}$ & $\mathbf{2 0 1 7}$ & $\mathbf{2 0 1 8}$ & $\mathbf{2 0 1 9}$ \\
\hline $\mathrm{X} 1$ & 0.002 & 0.002 & 0.002 & 0.001 & 0.002 \\
\hline $\mathrm{X} 2$ & 0.001 & 0.000 & 0.001 & 0.000 & 0.000 \\
\hline $\mathrm{X} 3$ & 0.002 & 0.002 & 0.002 & 0.002 & 0.001 \\
\hline $\mathrm{X} 4$ & 0.848 & 0.772 & 0.421 & 0.562 & 0.594 \\
\hline $\mathrm{X} 5$ & 0.472 & 0.429 & 0.436 & 0.487 & 0.521 \\
\hline $\mathrm{Z}$ & 1.325 & 1.206 & 0.861 & 1.053 & 1.119 \\
\hline $\mathrm{K}$ & $\begin{array}{l}\text { Distres } \\
\text { s Zone }\end{array}$ & $\begin{array}{l}\text { Distres } \\
\text { s Zone }\end{array}$ & $\begin{array}{l}\text { Distres } \\
\text { s Zone }\end{array}$ & $\begin{array}{l}\text { Distres } \\
\text { s Zone }\end{array}$ & $\begin{array}{l}\text { Distres } \\
\text { s Zone }\end{array}$ \\
\hline
\end{tabular}

Sumber: Pengolahan Data (2020)

Berdasarkan Tabel 2 dapat dilihat pada tahun kurun waktu 20152019 hasil perhitungan dengan menggunakan metode Altman Z-Score Perusahaan Gas Negara memperoleh nilai $\mathrm{Z}$ tertinggi pada tahun 2015 sebesar 1,32 dan terendah pada tahun 2017 sebesar 0,86. Hal ini mengartikan bahwa pada tahun 2015-2019 perusahaan mengalami Financial Distress karena $(Z<1,8)$. Hasil Perhitungan menunjukkan Perusahaan Gas Negara memperoleh nilai $\mathrm{Z}$ pada tahun 2019 sebesar 1,12 Perusahaan mengalami Financial Distress karena nilai yang didapatkan kurang dari nilai $\mathrm{Z}<1,8$.

Peningkatan yang paling dominan adalah X5 hal ini menunjukan bahwa perusahaan semakin baik perusahaan dalam menghasilkan laba dari total aktiva yang dimiliki perusahaan.

Penurunan yang paling dominan adalah X3 dan X4 hal ini menunjukan penurunan yang menunjukkan kemampuan perusahaan dalam mengelola laba menurun dan tidak efektifnya kemampuan perusahaan dalam memenuhi kewajibannya dari nilai pasar modal sendiri.

\section{Hasil Analisis Financial Distress Metode Altman Z-score PT. Leyand Internasional}

Tabel 3 Hasil Perhitungan Z-Score PT. Leyand Internasional

\begin{tabular}{llllll}
\hline Tahun & $\mathbf{2 0 1 5}$ & $\mathbf{2 0 1 6}$ & $\mathbf{2 0 1 7}$ & $\mathbf{2 0 1 8}$ & $\mathbf{2 0 1 9}$ \\
\hline $\mathrm{X} 1$ & 0.00 & 0.00 & 0.00 & -0.01 & -0.02 \\
\hline $\mathrm{X} 2$ & 0.00 & 0.00 & 0.00 & -0.02 & -0.05 \\
\hline $\mathrm{X} 3$ & 0.00 & 0.00 & 0.00 & -0.05 & -0.02 \\
\hline $\mathrm{X} 4$ & 1.38 & 1.56 & 1.77 & 4.28 & 7.43 \\
\hline $\mathrm{X} 5$ & 0.18 & 0.23 & 0.18 & 0.38 & 0.46 \\
\hline $\mathrm{Z}$ & 1.56 & 1.78 & 1.94 & 4.58 & 7.81 \\
\hline & $\begin{array}{l}\text { Distress } \\
\text { Ketegori }\end{array}$ & $\begin{array}{l}\text { Distress } \\
\text { Zone }\end{array}$ & $\begin{array}{l}\text { Grey } \\
\text { Zone }\end{array}$ & $\begin{array}{l}\text { Safe } \\
\text { Zone }\end{array}$ & $\begin{array}{l}\text { Safe } \\
\text { Zone }\end{array}$ \\
\hline
\end{tabular}

Sumber: Pengolahan data (2020)

Berdsasarkan tabel 3 dapat dilihat pada tahun kurun waktu 20152019 hasil perhitungan dengan menggunakan metode Altman Z-Score PT. Leyand Internasional. Pada tahun 2015 sampai 2016 mendapat nilai ZScore 1,56 pada tahun 2015 dan nilai $\mathrm{Z}$ score tahun 2016 sebesar 1,78 hal ini mengartikan bahwa PT. Leyand Internasional mengalami finansial distress karena memperoleh nilai $\mathrm{Z}$ dibawah 1,8 .

Penurunan yang paling dominan adalah X1 dan X2. Pada X1 menunjukan bahwa penurunan menandakan bahwa kondisi likuiditas yang semakin buruk karena modal kerjanya menyusut secara relatif terhadap total aset yang dimiliki perusahaan, sedangkan pada X2 mengalami penurunan yang tinggi menandakan bahwa laba ditahan sebagai sumber dana pengadaan aktiva kurang baik, ini mengindikasikan bahwa perusahaan sedang mengalami kerugian. 
Peningkatan yang paling dominan pada kurun waktu 2015 sampai 2016 adalah X3, X4 dan X5. pada variabel $\mathrm{X} 3$ yang menunjukan bahwa perusahaan sudah baik dan efektif dalam mengelola laba yang terus menurun. pada variabel X4 memberikan konrtibusi peningkatan Z-Score dari tahun 2015 sampai 2016. Artinya perusahaan sudah baik dalam memenuhi kewajibannya dari nilai pasar modal sendiri. Pada variabel X5 menunjukan peningkatan Z-Score pada kurun waktu 2015-2016. Hal ini menunjukan bahwa perusahaan telah secara optimal melakukan peningkatan volume penjualan.

Berdasarkan tabel 3 menunjukan bahwa tahun 2017 PT. Leyand Internasional berada pada area grey zone karena Z-Score PT. Leyand Internasional diantara 1,89-2,99. Setelah keluar dari kriteria distress zone, kondisi keuangan tahun 2017 PT. Leyand Internasional semakin membaik dapat dicerminkan melalui peningkatan pada variabel $X$. Hal ini menunjukan bahwa hal ini membuktikan bahwa perusahaan berusaha secara maksimal untuk mengelola seluruh elemen keuangannya sehingga dapat berfungsi lebih baik namun perusahaan tetap masih dalam kondisi rawan.

Berdasarkan tabel 3 menunjukan bahwa tahun 2018-2019 PT. Leyand Internasional berada pada area safe zone karena Z-Score PT. Leyand Internasional kondisi keuangan tahun 2018-2019 PT. Leyand Internasional semakin membaik setelah keluar dari kriteria grey zone. Hal ini memmbuktikan bahwa perusahaan berusaha secara maksimal untuk mengelola seluruh elemen keuangannya sehingga dapat berfungsi lebih baik.

Penurunan pada variabel X1 dan $\mathrm{X} 2$. Hal ini menunjukan bahwa Pada X1 menunjukan bahwa penurunan menandakan bahwa kondisi likuiditas yang semakin buruk karena modal kerjanya menyusut secara relatif terhadap total aset yang dimiliki perusahaan, sedangkan pada X2 mengalami penurunan yang tinggi menandakan bahwa laba ditahan sebagai sumber dana pengadaan aktiva kurang baik, ini mengindikasikan bahwa perusahaan sedang mengalami kerugian.

Peningkatan yang membaik pada tahun 2018 sampai 2019. Variabel yang mendominasi peningkatan $\mathrm{z}$-score adalah variabel $\mathrm{X} 5$ yang menggambarkan perusahaan sudah optimal dalam melakukan peningkatan volume penjualan. Peningkatan X5 diikuti dengan peningkatan variabel $\mathrm{X} 4$ hal ini menunjukan bahwa perusahaan sudah efektif dalam memenuhi kewajiban-kewajiban dari nilai pasar modal sendiri.

\section{Hasil Analisis Financial Distress Metode Altman Z-score PT. Rukun Raharja}

Tabel 4 Hasil Perhitungan Z-Score PT. Rukun Raharja

\begin{tabular}{llllll}
\hline Tahun & $\mathbf{2 0 1 5}$ & $\mathbf{2 0 1 6}$ & $\mathbf{2 0 1 7}$ & $\mathbf{2 0 1 8}$ & $\mathbf{2 0 1 9}$ \\
\hline $\mathrm{X} 1$ & 0.002 & 0.010 & 0.010 & 0.003 & 0.003 \\
$\mathrm{X} 2$ & 0.002 & 0.003 & 0.004 & 0.004 & 0.005 \\
\hline $\mathrm{X} 3$ & 0.003 & 0.002 & 0.004 & 0.003 & 0.002 \\
\hline $\mathrm{X} 4$ & 0.432 & 0.448 & 0.661 & 0.623 & 0.369 \\
\hline $\mathrm{X} 5$ & 1.278 & 1.286 & 0.988 & 0.617 & 0.676 \\
$\mathrm{Z}$ & 1.717 & 1.749 & 1.667 & 1.250 & 1.055 \\
\hline Kategori & $\begin{array}{l}\text { Distress } \\
\text { Zone }\end{array}$ & $\begin{array}{l}\text { Distress } \\
\text { Zone }\end{array}$ & $\begin{array}{l}\text { Distress } \\
\text { Zone }\end{array}$ & $\begin{array}{l}\text { Distress } \\
\text { Zone }\end{array}$ & $\begin{array}{l}\text { Distress } \\
\text { Zone }\end{array}$ \\
\hline
\end{tabular}

Sumber: Pengolahan Data (2020)

Berdasarkan Tabel 4 dapat dilihat pada tahun kurun waktu 20152019 hasil perhitungan dengan menggunakan metode Altman Z-Score PT. Rukun Raharja memperoleh nilai Z tertinggi pada tahun 2016 sebesar 1,74 dan terendah pada tahun 2019 sebesar 
1,05. Hal ini mengartikan bahwa pada tahun 2015-2019 perusahaan mengalami Financial Distress karena ( $Z$ $<1,8$ ). Hasil Perhitungan menunjukkan PT. Rukun Raharja memperoleh nilai $Z$ pada tahun 2019 sebesar 1,05 perusahaan mengalami Financial Distress karena nilai yang didapatkan kurang dari nilai $Z<1,8$.

Peningkatan yang paling dominan adalah X2 hal ini menunjukan bahwa perusahaan perusahaan sudah baik dan optimal dalam menghasilkan laba ditahan dari total aktiva yang dimiliki perusahaan.

Penurunan yang paling dominan adalah variabel X4 hal ini menunjukan bahwa tidak efektifnya kemampuan perusahaan dalam memenuhi kewajibannya dari nilai pasar modal sendiri.

\section{Hasil Analisis Financial Distress Metode Altman Z-score PT. Mitra Energi Perkasa}

Tabel 5.Hasil Perhitungan Z-Score PT. Mitra Energi Perkasa

\begin{tabular}{llllll}
\hline Tahun & $\mathbf{2 0 1 5}$ & $\mathbf{2 0 1 6}$ & $\mathbf{2 0 1 7}$ & $\mathbf{2 0 1 8}$ & 2019 \\
\hline $\mathrm{X} 1$ & 0.001 & 0.002 & 0.004 & 0.001 & 0.001 \\
\hline $\mathrm{X} 2$ & 0.009 & 0.007 & 0.007 & 0.013 & 0.012 \\
\hline $\mathrm{X} 3$ & 0.005 & 0.007 & 0.001 & -0.015 & 0.003 \\
\hline $\mathrm{X} 4$ & 0.018 & 0.017 & 0.020 & 0.021 & 0.017 \\
$\mathrm{X} 5$ & 1.171 & 1.060 & 1.215 & 0.564 & 1.262 \\
\hline $\mathrm{Z}$ & 1.203 & 1.093 & 1.248 & 0.585 & 1.296 \\
\hline Kategori & $\begin{array}{l}\text { Distress } \\
\text { Zone }\end{array}$ & $\begin{array}{l}\text { Distress } \\
\text { Zone }\end{array}$ & $\begin{array}{l}\text { Distress } \\
\text { Zone }\end{array}$ & $\begin{array}{l}\text { Distress } \\
\text { Zone }\end{array}$ & $\begin{array}{l}\text { Distress } \\
\text { Zone }\end{array}$ \\
\hline \multicolumn{2}{l}{ Sumber Pengolah Dat }
\end{tabular}

Sumber: Pengolahan Data (2020)

Berdasarkan Tabel 5 dapat dilihat pada tahun kurun waktu 20152019 hasil perhitungan dengan menggunakan metode Altman Z-Score PT. Mitra Energi Persada memperoleh nilai Z tertinggi pada tahun 2019 sebesar 1,296 dan terendah pada tahun 2018 sebesar 0,585. Hal ini mengartikan bahwa pada tahun 2015-2019 perusahaan mengalami Financial Distress karena $(\mathrm{Z}<1,8)$. Hasil Perhitungan menunjukkan PT. Mitra Energi Perkasa memperoleh nilai Z pada tahun 2019 sebesar 1,296 Perusahaan mengalami Financial Distress karena nilai yang didapatkan kurang dari nilai $Z<1,8$.

Penurunan yang paling dominan adalah variabel X2 hal ini menunjukan bahwa laba ditahan sebagai sumber dana pengadaan aktiva kurang baik, ini mengindikasikan bahwa perusahaan sedang mengalami kerugian.

Peningkatan yang paling dominan adalah variabel $\mathrm{X} 5$ hal ini menunjukan bahwa perusahaan mengalami peningkatan penjualan dan perusahaan berhasil meningkatkan volume bisnis yang cukup dibandingkan investasi dalam total aktivanya.

Hasil analisis terhadap 4 perusahaan energi yang diteliti menunjukkan bahwa sebagian perusahaan dalam kondisi distress, artinya perusahaan perlu meningkatkan kinerja keuangannya agar perusahaan berada dalam kondisi yang aman (safe).

Terdapat 1 perusahaan yaitu PT. Leyand Internasional dalam kondisi safe sehingga perusahaan harus berusaha tetap mempertahankan keadaannya agar tidak masuk dalam grey zones ataupun distress zones. Dari hasil penelitian terdapat tiga perusahaan berada dalam kondisi Distres Zones, perusahaan yang mengalami financial distress ini adalah PT. Perusahaan Gas Nergara, PT. Rukun Raharja, dan PT. Mitra energy Persada yang selama 5 tahun berada dalam posiis distres.

Variabel yang paling banyak mempengaruhi terjadinya penurunan nilai Z-Score adalah variabel X2 dimana perusahaan perlu mengoptimalkan kemampuannya dalam menghasilkan modal bersih dan laba 
dari keseluruhan aktiva yang dimiliki oleh perusahaan.

$$
\text { Menurut Hery (2017) }
$$

mengemukakan tentang faktor-faktor financial distress perusahaan yang dapat diklasifikasikan menjadi dua bagian, yaitu faktor internal perusahaan seperti kredit yang diberikan kepada pelanggan terlalu besar, lemahnya kualifikasi sumber daya manusia, kekurangan modal kerja, penyalahgunaan wewenang dan kecurangan. Sedangkan faktor eksternal perusahaan meliputi persaingan bisnis yang ketat, berkurangnya peminatan terhadap produk atau jasa yang dihasilkan, turunnya harga jual secara terus menerus dan kecelakaan atau bencana alam yang menimpa dan merugikan perusahaan sehingga mempengaruhi jalannya aktivitas perusahaan.

\section{PENUTUP}

\section{Kesimpulan}

Berdasarkan hasil penelitian diatas maka kesimpulan dalam penelitian ini menunjukan jasil prediksi financial distress perusahaan sub sektor energy yang berjumlah 4 perusahaan go public selama periode penelitian 2015 sampai 2019 dengan menggunakan metode Altman Z-Score. Setelah melakukan perhitungan Z-Score menghasilkan bahwa terdapat tiga perusahaan dalam kondisi finansial distress dan terdapat satu perusahaan yang berada pada safe area

\section{Saran}

$\begin{array}{rrr}\text { Setiap } & \text { perusahaaan sub sektor } \\ \text { energy } & \text { sebaiknya } & \text { mampu }\end{array}$ mengoptimalkan kemampuannya dalam menghasilkan modal bersih dan laba dari keseluruhan aktiva yang dimiliki oleh perusahaan agar perusahaan berada dalam kondisi yang aman (Safe Zone)

\section{DAFTAR PUSTAKA}

bps.go.id. Neraca Energi Indonesia. Diakses 10 November 2020, dari https://www.bps.go.id/publicatio $\mathrm{n} / 2019 / 12 / 24 / 2 \mathrm{c} 5 \mathrm{c} 26 \mathrm{f} 63 \mathrm{da} 23960$ $5 \mathrm{e} 0 \mathrm{a} 0 \mathrm{ca} 0 /$ neraca-energiindonesia-2014--2018-.html

Carnevela, C. R., \& Widyawati, N. (2017). Pengaruh Pertumbuhan Penjualan, Ukuran Perusahaan, dan Struktur Aktiva terhadap Struktur Modal. Jurnal Ilmu dan Riset Manajemen (JIRM), 6(3).

esdm.go.id. Outlook Energi Indonesia (2019). Diakses 10 November 2020, dari https://www.esdm.go.id/assets/m edia/content/content-outlookenergi-indonesia-2019-bahasaindonesia.pdf

Fahmi, I. (2017). Analisis Laporan Keuangan. Bandung: Alfabeta

Hariyani, Iswi., Serfianto., \& Cita Y. (2011). Merger. Konsolidasi, Akuisisi, \& Pemisahan Perusahaan: Cara Cerdas Mengembangkan \& Menajukan Perusahaan. Jakarta: Vidimedia

Hery. (2017). Auditing dan Asurans. Jakarta. Grasindo 